\title{
CONCEPÇÕES DE APRENDIZAGEM EM ESTUDANTES
}

UNIVERSITÁRIOS BRASILEIROS

\author{
Gustavo Lima Freire \\ António Manuel Duarte
}

Resumo: Este artigo relata parte dos resultados de um estudo que procurou caracterizar as concepções de aprendizagem de estudantes universitários brasileiros no enquadramento da perspectiva fenomenográfica. Entre outras dimensões, um grupo de estudantes foi entrevistado sobre o significado, o processo e o contexto da aprendizagem. As respostas foram sujeitas a uma análise de conteúdo que permitiu demonstrar uma replicação da maioria das concepções de aprendizagem descritas pela investigação fenomenográfica (isto é a distinção entre aprendizagem enquanto memorização e compreensão) bem como o surgimento de concepções aparentemente novas (isto é aprender é desenvolver concepções sobre as matérias e simultaneamente decorar e aplicar o conhecimento adquirido; aprende-se com os erros; sem exercer qualquer intenção ou esforço; de forma instintiva ou inata; colaborando; vivenciando; sentindo; brincando e observando). Algumas dessas concepções são interpretadas em função dos referentes culturais dos participantes.

Palavras-chave: Aprendizagem. Estudantes universitários. Fenomenografia. 


\section{Introdução}

Entre as perspectivas teóricas que actualmente delimitam a investigação psicológica sobre a aprendizagem no contexto académico, destacam-se a da "Aprendizagem autorregulada" (Zimmermam, 1998) e a das "Abordagens à Aprendizagem" (Marton \& Säljö, 1976). Esta última, na qual se enquadra o presente artigo, entende a aprendizagem dos estudantes como uma combinação entre o tipo de motivação face às tarefas e o tipo de estratégia por eles utilizado (Biggs, 1987). Assume assim um tema central à Psicologia Cognitiva e Educacional, que é o da existência de diferentes tipos de aprendizagem - a vários níveis de complexidade (Ausubel, Novak, \& Hanesian, 1978; Craik \& Lockhart, 1972). Vários estudos têm demonstrado que diferentes abordagens à aprendizagem condicionam distintos níveis de sucesso e qualidade na aprendizagem (Cliff, 1998; Grácio, 2002; Rendeiro \& Duarte, 2007; Rosário et al., 2006).

Na senda das primeiras investigações sobre abordagens à aprendizagem, Ference Marton e colaboradores, constituíram uma área de investigação - a Fenomenografia - que cedo se debruçou sobre outra variável decisiva - a concepção que os estudantes têm do fenómeno da aprendizagem. Efectivamente, as concepções de aprendizagem estão em estreita relação com as abordagens à aprendizagem, no sentido em que a "experiência de aprendizagem" é tida como o elemento central do processo de aprendizagem. Citando Marton e Booth (1997):

A fim de dar sentido à forma como as pessoas lidam com os problemas e as situações do mundo, temos de compreender a forma como elas vivenciam esses mesmos problemas e situações... a capacidade de agir de uma determinada maneira reflete a capacidade de experimentar algo de uma certa maneira. (p. 111)

Vários autores confirmam que a atuação dos estudantes é dirigida pelas suas concepções de aprendizagem, reafirmando a utilidade do seu mapeamento conceitual, não apenas para a compreensão dos insucessos acadêmicos, como também para a promoção de mudanças das próprias concepções de aprendizagem, tendo como objetivo último o agenciamento da autorregulação e a conquista de aprendizagens mais ricas (Biggs, 1990; Marton, 1988; Säljö, 1984).

Para a perspectiva fenomenográfica as concepções de aprendizagem são definidas como as diversas formas com as quais as pessoas representam esse fenômeno na consciência. As concepções de aprendizagem podem ser estudadas considerando várias dimensões da representação sobre a aprendizagem. Tradicionalmente consideram-se três dimensões: a dimensão referencial, que implica a definição da natureza do fenômeno (o que é a aprendizagem), a dimensão processual, que se refere à no- 
ção do processo de aprendizagem (como se aprende) e a dimensão contextual, que se relaciona ao momento, ao lugar ou às circunstâncias da aprendizagem (quando, onde, com quem e em que circunstâncias se aprende).

A conquista de aprendizagens mais profundas e funcionais implica a compreensão das diferentes formas com as quais os intervenientes dos processos educativos representam a aprendizagem, assim como a conscientização dessas representações. A posse desse conhecimento poderá ajudar a reconfigurar a forma de ensinar e aprender dos professores e estudantes.

Na medida em que os professores conheçam as concepções dos seus estudantes, poderão direcionar seu ensino e incentivar o uso de estratégias de aprendizagem mais construtivas e ou adaptadas (Entwistle, 1984).

A Fenomenografia adota como unidade de investigação o modo como os indivíduos representam (graficam) a aprendizagem. $O$ seu objeto de pesquisa é a variação dessas formas de experiência e o seu método é o da análise qualitativa de transcrições de entrevistas semiestruturadas.

De acordo com as evidências recolhidas pela sua investigação existem basicamente duas formas de conceber o fenômeno da aprendizagem. Uma que vê a aprendizagem como aquisição mecânica de conhecimentos (concepção quantitativa) e outra que a vê como compreensão do conhecimento (concepção qualitativa).

A primeira toma a aprendizagem enquanto uma atividade memorística, como uma recolha e acumulação mecânica da informação, com o objetivo de retratá-la nas situações de avaliação. A aprendizagem é considerada como uma atividade estereotipada, exigindo relativamente pouco do indivíduo, sendo vista como conducente a "uma grande e colorida manta de retalhos, a qual se vai acrescentando novos pedaços" (Laurillard, 1979). Essa concepção encara a aprendizagem com base num modelo aditivo onde as partes se adicionam ao todo sem a necessidade de articular, relacionar, reconstruir ou reacomodar a informação ou o conhecimento (Biggs \& Moore, 1993). As informações podem ser parcialmente ou eventualmente compreendidas, atendendo apenas ao desejo de poder ser utilizadas numa prova, embora depois possam ser esquecidas (Biggs, 1990).

A segunda concepção de aprendizagem define essa como uma atividade estratégica, baseada na compreensão e/ou na construção do conhecimento, conseguida através de um processo de abstração de significados, da interpretação pessoal da informação e do relacionamento do conhecimento formal com a realidade e a experiência, resultando num crescimento pessoal (Biggs, 1990) e possibilitando uma interpretação, aceitação ou contestação da informação, promovida pela alteração de perspectivas. Ela basear-se-ia num modelo sistémico, segundo o qual os 
conhecimentos novos incitariam uma nova organização pessoal e uma nova forma de se relacionar com o conhecimento anterior e com as experiências pessoais (Biggs \& Moore, 1993; Marton \& Säljö, 1997).

Os estudantes que possuem uma concepção quantitativa tendem a aprender principalmente para a "escola", revelando uma aprendizagem rotineira, ingênua e elementar, manifestada por uma visão do conhecimento como algo estático, discreto e objetivo, pronto para ser utilizado na sua forma menos refinada. Enquanto os que possuem uma concepção qualitativa tendem a aprender para a vida e a apresentar uma aprendizagem mais sofisticada; utilizando um pensamento mais coerente, organizado e voltado para uma construção progressiva (Biggs, 1989).

A diferenciação entre aprendizagens mais e menos desenvolvidas constitui um conceito com uma larga história. Da vasta discussão que aí se apresenta, realizaremos um recorte, apanhando uma categoria central dos argumentos de Paulo Freire (2003). A sua obra classifica a pedagogia como "bancária" ou "problematizadora", ambas determinadas pelas concepções construídas e construtoras das relações sociais. No primeiro caso, de um sistema de educação binário e vertical, o educador é o sujeito da ação, a quem caberia prescrever e depositar os conhecimentos, enquanto o educando é o objeto, a quem caberia arquivá-los. A consciência bancária "pensa que quanto mais se dá mais se sabe. Mas a experiência revela que com este mesmo sistema só se formam indivíduos medíocres, porque não há estímulo para a criação" (Freire, 2003, p. 38).

Seguindo essa lógica, a categoria bancária se associaria às aprendizagens baseadas na acumulação do conhecimento (concepção quantitativa) enquanto a problematizadora às aprendizagens baseadas na compreensão e consequente transformação do conhecimento (concepção qualitativa).

Os estudos também sugerem que aqueles estudantes que possuem uma concepção qualitativa normalmente tendem a valorizar mais a aprendizagem (Marton, Dall'Alba, \& Beaty, 1993) o que poderia levá-los a manterem-se na vida acadêmica por mais tempo, ao contrário do que aconteceria com aqueles que possuem uma concepção quantitativa.

Embora a concepção quantitativa possa mostrar-se suficiente quando as tarefas requerem a aprendizagem de conteúdos simples ou a aquisição de competências básicas, seja importante para a retenção do significado das mensagens compreendidas e consequentemente para a aplicação do conhecimento às novas situações, é deficitária para a aprendizagem de conteúdos de nível superior. Por isso, e inclusive porque a concepção qualitativa de uma certa forma engloba a outra, existe uma hierarquia entre elas, sendo, portanto, a qualitativa considerada mais avançada do que a quantitativa (Marton \& Booth, 1997; Cliff, 1998).

Foi ainda sugerida a existência de uma concepção "institucional" da aprendizagem, que apesar de pouco estudada e menos consistente, 
corresponderia a uma forma de representar a aprendizagem enquanto sucesso acadêmico, ou seja, a prova de que a aprendizagem teria ocorrido seria ter passado e/ou ter obtido boas notas. Esse tipo de concepção não ocorreria independentemente da concepção quantitativa ou qualitativa, mas associada a uma delas (Biggs \& Moore, 1993).

Recentemente, a investigação propôs ainda a existência de duas novas concepções de aprendizagem: a concepção "intermédia" e a "comunitária". A concepção "intermédia" representa a aprendizagem não apenas como uma memorização mecânica da informação, conseguida através de uma "abordagem de superfície" à aprendizagem, mas como uma memorização dirigida à compreensão, conquistada pela utilização de uma "abordagem de profundidade" à aprendizagem (Marton \& Booth, 1997).

A concepção "comunitária" apresenta uma vertente mais social e coletiva. Encerra a noção de aprendizagem como uma obrigação em relação à comunidade, contrariamente à habitual perspectiva individualista. Esse tipo tanto pode associar-se à qualitativa como à quantitativa, quando o que se espera é a compreensão ou a acumulação do conhecimento para atender o objetivo de cumprir um dever social (Cliff, 1998).

As duas principais concepções de aprendizagem - a quantitativa e a qualitativa - obedecem a uma diferenciação que faz emergir variantes da noção de aprendizagem enquanto acumulação e enquanto compreensão de conhecimento. Uma das mais importantes taxonomias empíricas descritivas da variedade de concepções de aprendizagem é a de Marton et al. (1993): Aumento de conhecimento; Memorização e reprodução; Aplicação; Compreensão; Reinterpretação; Mudança pessoal.

Steketee (1997, citado por Rosário et al., 2006) investigou concepções de aprendizagem em estudantes com cinco, oito e onze anos, tendo identificado seis concepções distintas e similares às identificadas por Marton et al. (1993): a) aprendizagem genérica; b) realização física;c) saber mais coisas; d) saber coisas mais difíceis; e) procurar o sentido e f) construir novas compreensões.

Rosário et al. (2006) num estudo que pretendeu mapear as concepções de aprendizagem de um grupo de estudantes do $5^{\circ}$ ano de escolaridade e dos seus encarregados de educação detectaram concepções correspondentes às identificadas por Marton et al. (1993) e também concepções emergentes. Os resultados demonstraram que tanto os pais quanto os filhos conceitualizam a aprendizagem como um fenômeno processual, mas enquanto os primeiros realçam o seu aspecto processual experiencial, os segundos realçam o seu caráter instrumental. Aprender-se-ia por observação, interagindo com os outros, através de um processo lúdico e vivenciando as situações.

Tem sido empreendido na Faculdade de Psicologia da Universidade de Lisboa um programa de investigação com o objetivo de compreen- 
der as concepções de e as abordagens à aprendizagem em geral e para diferentes atividades acadêmicas.

Duarte $(2000,2004)$, num estudo que procurou caracterizar as concepções de aprendizagem de estudantes universitários portugueses, identificou concepções anteriormente descritas pela investigação fenomenográfica (distinção entre aprendizagem enquanto memorização e enquanto compreensão; aprendizagem enquanto conjugação da memória com a compreensão), uma concepção nova (aprendizagem como compreensão e aplicação do conhecimento) e variantes de algumas concepções conhecidas (aprende-se praticando exploratoriamente; por compreensão da aprendizagem; através da motivação).

Rendeiro e Duarte (2007), num estudo com estudantes portugueses do $12^{\circ}$ ano, que pretendeu identificar as concepções de aprendizagem para as situações de avaliação, comprovaram a correspondência de concepções de aprendizagem para a avaliação com a maioria das concepções de aprendizagem desveladas pela Fenomenografia.

Os seus resultados apontaram que a aprendizagem face à avaliação pode ser concebida como um processo de armazenamento, memorização e aplicação da informação (forma quantitativa) sendo o objetivo do estudante o de reproduzir e aplicar tal informação durante o momento avaliativo. Pelo contrário, pode ser concebida de modo mais rico (forma qualitativa) quando representada enquanto processo de reestruturação do conhecimento, desenvolvimento de novas perspectivas e mudança pessoal.

Foi representada através de uma concepção intermédia (quando a avaliação é vista como uma atividade que conjuga a memorização com a compreensão) e como forma de obter classificações, o que corresponderia à concepção institucional proposta por Biggs $(1989,1990)$ e Biggs e Moore (1993). E ainda como um processo autorregulatório, que aponta para o planear e monitorar da ação e das tarefas e o autoavaliar e o retificar dos procedimentos.

Rebelo e Duarte (em preparação), num estudo que pretendeu mapear as concepções de aprendizagem com o computador de um grupo de estudantes universitários portugueses, registraram a presença de uma concepção quantitativa, quando o aprender com o computador é visto enquanto acumulação de informação por memorização, e a presença de uma concepção qualitativa, quando o aprender com o computador é tido como um processo de compreensão e/ou transformação do conhecimento, o que poderia resultar numa mudança pessoal. Registraram, ainda, uma concepção institucional, quando o aprender com o computador é visto como um auxílio na obtenção de classificações mais elevadas.

No Brasil, o estudante universitário ainda tem sido pouco abordado nos trabalhos de pesquisa. No geral, sendo constituído como partici- 
pante dos estudos e não como foco específico de investigação (Mercuri \& Polydoro, 2004). Litto (n.d.) afirma que:

estamos produzindo gerações de profissionais mal preparados... Um bom exemplo disso é a falta de discussão no Brasil sobre um conceito significativo e bastante presente na literatura científica mundial... Durante os últimos vinte anos; considerável pesquisa tem sido realizada sobre a distinção entre dois "estilos" de ensino e aprendizagem, um designado "aprendizagem profunda", e o outro "aprendizagem de superfície".

Como as concepções de aprendizagem não são construções inteiramente individuais (psicológicas) e nem inteiramente sociais (contextuais), mas o resultado da relação entre essas duas dimensões, e considerando que muitos outros fatores condicionam a forma de conceber um fenômeno, incluindo a influência da internacionalização dos sistemas de ensino, podemos considerar que existem formas universais de representar a aprendizagem, como também variação nos modos de conceber tal fenômeno em função das maneiras características de experienciar e significar um fenômeno numa dada cultura.

Marton, Wen e Nagle (1996, citado por Grácio, 2002), num estudo comparativo com estudantes universitários chineses e uruguaios, verificaram que os dois grupos apresentavam resultados complementares. Enquanto o grupo de estudantes chineses enfatiza mais o processo de aprendizagem, os uruguaios destacam mais os produtos (permanência do conhecimento dentro de si).

Purdie, Hattie e Douglas (1996, citado por Grácio, 2002) desenvolveram um estudo com o objetivo de compreender as concepções de aprendizagem de dois grupos de estudantes, um de nacionalidade australiana e o outro de japonesa. Os resultados demonstraram a existência de nove categorias: a) aprendizagem como aumento do conhecimento; b) aprendizagem como memorização, reprodução e estudo; c) aprendizagem como um meio para um fim; d) aprendizagem como compreensão; e) aprendizagem como ver algo de uma forma diferente; f) aprendizagem como realização pessoal; g) aprendizagem como dever; $h$ ) aprendizagem como um processo não limitado pelo tempo ou contexto e i) aprendizagem como desenvolvimento de competência social.

Esses estudos confirmam que a aprendizagem é representada dentro de um contexto social e cultural, donde valerá a pena prestar a atenção não à aprendizagem fora de um contexto, mas imbricada nele. Assim, as investigações devem se centrar no estudante em seu ambiente circundante (Marton, 1988). 


\section{Método}

Para esse estudo, que procurou caracterizar as concepções de aprendizagem no contexto brasileiro, a amostra de 15 participantes foi extraída da população dos estudantes universitários que frequentavam o primeiro ano ( $1^{\circ} \mathrm{e} 2^{\circ}$ períodos) de um curso de Psicologia. A sua idade variou entre 17 e 25 e a média foi de 20.31 anos. Relativamente à distribuição da variável sexo, 14 eram do sexo feminino e um do masculino.

Com o objectivo de caracterizar as concepções de aprendizagem dos participantes foram-lhes colocadas as seguintes questões abertas: "O que é aprender?" (correspondente à dimensão referencial); "Como se aprende?" (correspondente à dimensão processual);"Aonde se aprende?" (correspondente à dimensão contextual); "Quais são os fatores que influenciam a aprendizagem?" (correspondente à dimensão fatorial) e"Qual é a função da aprendizagem?" (correspondente à dimensão funcional). Como já foi referido, neste artigo relataremos apenas os resultados encontrados para as três primeiras questões. Para além disso, os estudantes eram informados que não deviam centrar-se na forma particular como aprendiam, mas sim na aprendizagem em geral. Salientava-se também a inexistência de respostas certas ou erradas, a confidencialidade e a voluntariedade.

A análise das respostas foi constituída por uma análise de conteúdo, que envolveu três momentos principais: 1) opção por um critério de segmentação das unidades a categorizar; 2) desenvolvimento de um sistema de categorias de análise; 3 ) testagem de confiança das categorias detectadas por comparação entre juízes.

O critério utilizado para a segmentação das unidades a categorizar foi o de "segmentação por unidades temáticas" (Flores, 1994), ou seja, todo o segmento de resposta que abordasse, pelo seu conteúdo, qualquer das dimensões focadas do fenômeno da aprendizagem (isto é referencial $(R)$, processual (P), contextual (C)) era considerado como uma unidade a categorizar, por correspondência com uma das categorias da respectiva dimensão (do sistema em desenvolvimento).

Considerando a crítica ao método "fenomenográfico", de que este aliena os participantes dos seus depoimentos, ao isolar e retirar frases soltas do contexto em que estas foram produzidas (Säljö, 1984) a categorização procurou ser sensível à totalidade de cada resposta, de acordo com a sugestão de Svensson (1989, citado por Eklund-myrskog, 1998). Não foram consideradas respostas em que os indivíduos se referiram ao seu modo próprio de aprendizagem.

Para o desenvolvimento de um sistema de categorias de análise utilizou-se uma aproximação intermédia entre as abordagens "indutiva" e "dedutiva" (Miles \& Huberman, 1994), ou seja, partimos de um modelo 
teórico (isto é o "fenomenográfico") para analisar os dados,"filtrando-os" sempre que possível com base em categorias de análise preexistentes.

Simultaneamente, tentou-se manter a sensibilidade aos aspectos não previstos, reformulando-se o modelo de partida com base em categorias emergentes. Assim, com base no sistema das seis concepções de aprendizagem descrito por Marton et al. (1993), procedemos a uma primeira análise das respostas com o objetivo de verificar quais as categorias que eram confirmadas pelo contexto específico desse estudo, quais as categorias infirmadas e quais as emergentes. Com base nos resultados desta primeira análise foi possível chegar a um segundo sistema de categorias de descrição das concepções de aprendizagem, que foi depois utilizado numa segunda análise das respostas por dois juízes.

Numa "fase de formação dos juízes" estes procederam à leitura e discussão interpretativa do segundo sistema de categorias. Seguidamente, cada juiz procedeu à categorização independente de cerca de $20 \%$ das respostas. Foi depois estudado, com base em tabelas de contingência, o padrão de acordo/desacordo entre os dois juízes.

Atendendo à detecção, por um dos juízes, de categorias não previstas no segundo sistema de categorização, foi posteriormente construído um terceiro e último sistema, com base no qual cada juiz procedeu à categorização independente de todas as respostas. Em seguida procedemos aos cálculos finais de acordo.

Para efeitos de classificação final das respostas, a resolução dos desacordos foi efetuada por discussão conducente a uma categorização consensual. Cada juiz procedeu ainda a verificação da correção da sua categorização, tal como sugerido por Garcia (1996). Na tabela 1 discrimina-se o acordo inter-juízes em cada dimensão. Como se pode observar, a magnitude de acordo entre juízes foi, para todas as dimensões, superior ou igual a $82 \% .^{1}$

Quadro 1. Acordo final inter-juízes quanto às categorias de cada dimensão

\begin{tabular}{|c|c|c|c|}
\hline Dimensão & $\begin{array}{c}\text { Frequência } \\
\text { de desacordo }\end{array}$ & $\begin{array}{c}\text { Frequência } \\
\text { de acordo }\end{array}$ & $\begin{array}{c}\text { Coeficiente } \\
\text { de acordo }\end{array}$ \\
\hline Referencial & 11 & 55 & $83 \%$ \\
Processual & 19 & 89 & $82 \%$ \\
Contextual & 0 & 33 & $100 \%$ \\
\hline
\end{tabular}

1 Para os cálculos de coeficiente de acordo foi usada a fórmula sugerida por Bakeman e Gottman (1986, citados por Rendeiro \& Duarte, 2007): $\mathrm{PA}=(\mathrm{Na} /(\mathrm{Na}+\mathrm{Nd})) 100$ na qual "PA" é percentagem de acordo;" $\mathrm{Na}^{\prime}$ é frequência de acordo e "Nd" frequência dos desacordos. 


\section{Resultados}

A análise dos resultados permitiu confirmar a presença, neste contexto, das seis concepções específicas descritas por Marton et al. (1993), ou seja, também aqui o aprender é tido como: 1) aumento de conhecimento (53.3\%); 2) memorização e reprodução (13\%); 3) memorização e aplicação (20\%); 4) compreensão (33.3\%); 5) reinterpretação $(6.6 \%) ; 6)$ mudança pessoal (40\%).

Registrou-se igualmente a presença de uma concepção de aprendizagem enquanto conjugação entre a memorização e compreensão da informação (20\%) análoga à concepção "intermédia" referida por Marton e Booth (1997) ou Cliff (1998).

Relativamente à dimensão referencial (isto é, o que é aprender), é de referir a emergência de um tipo de resposta não previsto, e que sugere a necessidade de propor uma concepção de aprendizagem nova. Chamaremos essa de "memorização, compreensão e aplicação (6.6\%)" por implicar uma definição da aprendizagem como um processo de desenvolvimento de concepções sobre as matérias, memorização e aplicação do conhecimento adquirido. Pode-se consultar uma síntese dos resultados relativos à dimensão referencial (ilustrados com exemplos de respostas) na tabela 2.

Relativamente à dimensão processual(isto é, como se aprende), para além das respostas que coincidiram com as noções documentadas de que se aprende armazenando (20\%), aplicando (13.3\%) e/ou compreendendo (26.6\%) as informações, conjugando a memorização e a compreensão (6.6\%), modificando-se (6.6\%), colaborando (73.3\%), vivenciando (53.3\%), brincando (13.3\%) e observando (46.6\%) foi possível registrar a emergência de respostas não previstas, que refletiram o processo de aprendizagem como isento de qualquer tipo de esforço por parte de quem aprende $(6.6 \%)$, como instintivo ou inato $(13.3 \%)$, de ensaio e erro (33.3\%) e que se daria através das emoções e sentimentos (6.6\%). Podese consultar uma síntese dos resultados relativos à dimensão processual (ilustrados com exemplos de respostas) na tabela 3.

Relativamente à dimensão contextual (isto é, aonde se aprende), todas as respostas coincidiram com as noções documentadas de que se aprende no contexto alargado do ambiente, ou seja, aprende-se em qualquer lugar e a qualquer momento. Por exemplo:"[aprende-se] em qualquer lugar, não precisa ser na escola ou na faculdade". 
Quadro 2.Concepções de aprendizagem - Dimensão Referencial -

O que é aprender

\begin{tabular}{|c|c|c|}
\hline Categorias & Descrição & Resposta ilustrativa \\
\hline Vaga & $\begin{array}{c}\text { Ausência de definição; } \\
\text { sinônimos sem qualificação }\end{array}$ & $\begin{array}{l}\text { "Aprendizagem é um } \\
\text { conceito de vida" }\end{array}$ \\
\hline $\begin{array}{l}\text { Aquisição de } \\
\text { informação }\end{array}$ & Aumentar conhecimentos & $\begin{array}{l}\text { "É uma bagagem bem } \\
\text { recheada" }\end{array}$ \\
\hline $\begin{array}{l}\text { Memorização e } \\
\text { reprodução }\end{array}$ & $\begin{array}{l}\text { Decorar e reproduzir a } \\
\text { informação armazenada }\end{array}$ & $\begin{array}{c}\text { "O modo que a gente } \\
\text { capta as coisas pra poder } \\
\text { repassar" }\end{array}$ \\
\hline $\begin{array}{l}\text { Memorização e } \\
\text { aplicação }\end{array}$ & $\begin{array}{c}\text { Decorar e aplicar a } \\
\text { informação armazenada }\end{array}$ & $\begin{array}{l}\text { "Aprendizagem pra mim } \\
\text { é acumular conhecimentos } \\
\text { e tá também aplicando } \\
\text { esses conhecimentos" }\end{array}$ \\
\hline Intermédia & $\begin{array}{l}\text { Desenvolver concepções } \\
\text { sobre as matérias e decorar }\end{array}$ & $\begin{array}{l}\text { "É você ir armazenando... } \\
\text { aquilo que você tá } \\
\text { entendendo". }\end{array}$ \\
\hline $\begin{array}{l}\text { Memorização, } \\
\text { compreensão e } \\
\text { aplicação }\end{array}$ & $\begin{array}{c}\text { Desenvolver concepções } \\
\text { sobre as matérias, decorar } \\
\text { e aplicar o conhecimento } \\
\text { adquirido }\end{array}$ & $\begin{array}{l}\text { "É entender, pra poder } \\
\text { aprender alguma coisa } \\
\text { é preciso saber pra que } \\
\text { aquilo vai servir... aí eu } \\
\text { vou memorizar" }\end{array}$ \\
\hline Compreensão & $\begin{array}{c}\text { Desenvolver concepções } \\
\text { sobre as matérias }\end{array}$ & $\begin{array}{l}\text { "Você não decorar, mas } \\
\text { você entender aquilo tá } \\
\text { sendo passado". }\end{array}$ \\
\hline $\begin{array}{l}\text { Compreensão } \\
\text { interpretativa }\end{array}$ & $\begin{array}{c}\text { Compreender e mudar } \\
\text { a concepção que se tem } \\
\text { da matéria }\end{array}$ & $\begin{array}{l}\text { "A gente muda certos } \\
\text { conceitos" }\end{array}$ \\
\hline Autoatualização & $\begin{array}{l}\text { Mudar a concepção que } \\
\text { se tem das coisas e mudar } \\
\text { também como pessoa }\end{array}$ & $\begin{array}{l}\text { "Acho que é aí que entra } \\
\text { aprendizagem, poder } \\
\text { modificar a pessoa, ela está } \\
\text { sempre se renovando". }\end{array}$ \\
\hline
\end{tabular}


Quadro 3. Concepções de aprendizagem - Dimensão Processual -

Como se aprende

\begin{tabular}{|c|c|c|}
\hline Categoria & Descrição & Resposta ilustrativa \\
\hline Armazenando & $\begin{array}{c}\text { Armazenando informação } \\
\text { por acrescento à } \\
\text { informação existente }\end{array}$ & $\begin{array}{l}\text { "Ninguém nasce sabendo, } \\
\text { mas com o tempo ela vai } \\
\text { aprendendo as coisas, } \\
\text { vai acumulando } \\
\text { conhecimentos" }\end{array}$ \\
\hline Aplicando & $\begin{array}{l}\text { Utilizando a informação } \\
\text { armazenada }\end{array}$ & $\begin{array}{l}\text { "Essa é uma boa maneira } \\
\text { de a gente vê o que } \\
\text { realmente a gente tá } \\
\text { aprendendo, aplicando" }\end{array}$ \\
\hline $\begin{array}{l}\text { Não intencio- } \\
\text { nalmente }\end{array}$ & $\begin{array}{c}\text { Sem exercer qualquer } \\
\text { tipo de esforço }\end{array}$ & $\begin{array}{c}\text { "É uma coisa que } \\
\text { acontece naturalmente" }\end{array}$ \\
\hline Instintivamente & De forma inata ou instintiva & $\begin{array}{l}\text { "É você que vai ter aquele } \\
\text { instinto" }\end{array}$ \\
\hline Compreendendo & $\begin{array}{c}\text { Desenvolvendo uma } \\
\text { concepção sobre a matéria }\end{array}$ & $\begin{array}{l}\text { "Você pode tá... estudando, } \\
\text { mas... não tá entendendo } \\
\text { nada... decorar é bem } \\
\text { diferente de você } \\
\text { realmente aprender". }\end{array}$ \\
\hline Conjugando & $\begin{array}{c}\text { Compreendendo e } \\
\text { memorizando a informação }\end{array}$ & $\begin{array}{l}\text { "Você colocar na memória } \\
\text { de longo prazo... você vai } \\
\text { voltar a lembrar daquilo } \\
\text { que você entendeu" }\end{array}$ \\
\hline Modificando-se & $\begin{array}{c}\text { Desenvolvendo uma } \\
\text { concepção sobre a matéria } \\
\text { e mudando como pessoa }\end{array}$ & $\begin{array}{c}\text { "Aquele conhecimento que } \\
\text { eu absorvo tipo imitador } \\
\text { não é útil, mesmo que eu } \\
\text { utilize não é exatamente } \\
\text { evoluir" }\end{array}$ \\
\hline Colaborando & $\begin{array}{c}\text { Através da interação } \\
\text { estabelecida com as } \\
\text { outras pessoas }\end{array}$ & $\begin{array}{c}\text { "Principalmente com a troca } \\
\text { de conhecimento" }\end{array}$ \\
\hline Ensaiando e & $\begin{array}{c}\text { Com os erros ou por } \\
\text { processos de tentativa } \\
\text { e erro }\end{array}$ & $\begin{array}{l}\text { "Quando a gente vê que } \\
\text { aquilo deu errado; a } \\
\text { gente não vai fazer aquilo } \\
\text { de novo do mesmo jeito, } \\
\text { a gente já procura outra } \\
\text { maneira de fazer" }\end{array}$ \\
\hline Vivenciando & Experienciando os fenômenos & "Através da experiência" \\
\hline Sentindo & $\begin{array}{l}\text { Através das emoções } \\
\text { e sentimentos }\end{array}$ & $\begin{array}{l}\text { "O nosso quotidiano nos } \\
\text { causa sensações, sejam } \\
\text { elas internas ou externas, } \\
\text { pode mexer com o nosso } \\
\text { sentimento mesmo, } \\
\text { felicidade, tristeza, raiva, } \\
\text { alegria, tudo isso" }\end{array}$ \\
\hline
\end{tabular}




\begin{tabular}{|l|c|c|}
\hline Brincando & Através do processo lúdico & $\begin{array}{c}\text { "Acho interessantíssima } \\
\text { à forma das crianças }\end{array}$ \\
\hline Observando & $\begin{array}{c}\text { aprenderem brincando" } \\
\text { "Observando... você } \\
\text { está aprendendo" }\end{array}$ \\
\hline
\end{tabular}

\section{Discussão dos resultados}

Relativamente à dimensão referencial (R) identificamos correspondentes para todas as categorias descritas por Marton et al. (1993) e correspondentes para categorias anteriormente descritas em Portugal (Duarte, 2000).

As categorias "Aquisição de informação," "Memorização e reprodução," "Memorização e aplicação,", “Compreensão", "Compreensão interpretativa" e "Autoatualização" encontram correspondentes diretos no sistema descrito por Marton et al. (1993).

A categoria "Intermédia", por sua vez, também encontra correspondente nos estudos de Duarte (2000). Além dessas, foi possível constatar o surgimento de uma nova categoria, denominada "Memorização, Compreensão e Aplicação". Essa concepção não consta dos sistemas propostos pela Fenomenografia e parece ser uma diferenciação da concepção "Intermédia" referida por Cliff (1998) e Duarte (2000) por acrescentar à concepção de aprendizagem enquanto memorização e compreensão dos fenômenos, uma noção "prática", salientando a necessidade de fazer uso desse conhecimento.

A partir da análise do discurso dos estudantes foi possível observar que, embora esses tivessem uma forma particular de expressão, as suas concepções de aprendizagem replicam, em grande medida, às anteriormente referidas pela investigação fenomenográfica, o que poderia talvez ser explicado pela tendência da uniformização dos sistemas de ensino. Essa uniformização talvez venha produzindo reflexos também na forma das pessoas conceberem o fenômeno da aprendizagem.

Um número de estudantes, mais alto do que seria esperado nesse nível de escolaridade, apresenta concepções de aprendizagens pouco articuladas, o que denota a necessidade de uma maior reflexão sobre o fenômeno da aprendizagem por parte dos estudantes. Para mais da metade dos estudantes o aprender é visto como aumento de conhecimentos, dado que pode ser interpretado aceitando essa concepção como sendo aquela a partir da qual todas as outras se desenvolvem (Marton et al., 1993).

A replicação geral do sistema fenomenográfico de concepções de aprendizagem encontrada nesse estudo pode estar associada ao processo de globalização dos sistemas educativos. Essas concepções (represen- 
tações do fenômeno da aprendizagem) foram divididas em três concepções básicas:"Quantitativa",em que a aprendizagem é vista de forma mais estereotipada (1.Vaga; 2. Aquisição de Informação; 3. Memorização e Reprodução; 4. Memorização e Aplicação); "Qualitativa", quando a aprendizagem é vista de forma mais estratégica, mais elaborada, e com uma noção de significado mais aberta (7. Compreensão; 8 . Compreensão Interpretativa; 9. Autoatualização) e "Intermediária" (5. Intermédia; 6. Memorização, Compreensão e Aplicação) (Säljö, 1984).

Houve uma predominância moderada da concepção "Qualitativa", embora fosse desejável e suposto que, no nível universitário, tais concepções fossem ainda mais representativas. Para um número representativo dos estudantes a aprendizagem é apenas um fenômeno reprodutivo. Uma parte deles referiu quer uma concepção "Quantitativa", quer uma concepção"Qualitativa"Vale ressaltar que nesse estudo não foi confirmada a existência da concepção "Institucional" (Biggs \& Moore, 1993).

Embora a literatura refira recorrentemente que a definição geral da aprendizagem, conseguida principalmente a partir da pergunta "O que é aprender?" ocupa lugar de destaque na conceitualização dos sujeitos, nesse estudo percebemos que houve uma certa resistência por parte dos estudantes para responderem tal questão, resistência que pode ter se apresentado pelo fato dessa questão ter sido a primeira. E já que pareceu a mais difícil, talvez tivesse sido importante começar as entrevistas a partir de uma outra questão. Uma outra explicação pode ser o fato de, como afirmam os próprios estudantes, nunca terem parado para refletir sobre a aprendizagem. Entre as cinco perguntas realizadas, essa pareceu realmente a mais difícil para quem respondeu e por isso mesmo a que aparentemente promoveu menos resultados.

Para cada dimensão, na prática, representada por uma pergunta específica, houve respostas que se relacionavam diretamente com o que foi perguntado, mas, principalmente respostas relacionadas às outras dimensões do aprender. Assim, muitas das concepções de aprendizagem em geral foram categorizadas a partir das respostas conferidas à pergunta "Como se aprende?", por exemplo, tendo, mesmo, sido difícil estabelecer uma diferenciação muito clara do que seria a aprendizagem no geral e a forma como se poderia aprender.

A dificuldade demonstrada pelos estudantes para responder essas perguntas de forma mais ou menos específica e clara pode indicar uma certa preferência por algum aspecto em detrimento dos outros. Será que os sistemas educativos não têm descurado a importância de contemplar o fenômeno da aprendizagem como multifacetado, atribuindo importância a cada uma das suas várias dimensões?

As situações de aprendizagem são constituídas pelas formas de conceber o aprender, nas suas variadas dimensões. As universidades podem contribuir para o melhoramento das aprendizagens, se ajudarem os 
estudantes a refletirem profundamente sobre o que é aprender, como se pode aprender e aonde se pode aprender.

Quanto à dimensão processual, identificamos a presença de categorias para as quais existem correspondentes na literatura. As categorias "Armazenando", "Aplicando", "Compreendendo" e "Modificando-se" possuem correspondência com categorias descritas por Marton et al. (1993). A categoria "Conjugando" encontra correspondente nos sistemas de Duarte (2000) e as categorias "Colaborando,",Vivenciando","Brincando" e "Observando" encontram correspondentes nos estudos de Rosário et al. (2006).

Além dessas, foi possível identificar o surgimento de quatro novas categorias. A primeira, denominada "Não intencionalmente", representa a idéia de que se aprende sem qualquer tipo de esforço. Esse dado pode significar uma necessidade tanto dos estudantes quanto da instituição de promover uma reflexão acerca da necessidade de procedimentos deliberados por parte de quem aprende. É importante salientar que a investigação realça a importância da ação intencional do estudante no processo de aprendizagem (Zimmerman, 1986).

A segunda, denominada "Instintivamente", se reporta à aprendizagem como um fenômeno "inato", portanto, inerente aos seres humanos. Tal categoria também pode significar uma certa renúncia à necessidade do comportamento intencional. Por outro lado, essas duas categorias também podem ser explicadas através do conceito teórico da aprendizagem automática, tão necessária e importante para as tarefas cognitivas superiores.

A terceira categoria, "Ensaiando e errando", refere que se aprende com os erros, por processos de ensaios. Embora essa categoria possa ser compreendida como uma representação do modelo comportamental, em que o sistema de reforço determina o comportamento desejável, nos parece que a própria capacidade de refletir sobre novas possibilidades, eliminando os desacertos e podendo reconstruir os percursos, se aproxima do construtivismo.

A categoria "Sentindo" refere que se aprende através das emoções e sentimentos. Ainda que tenha se apresentado de forma relativamente tímida, na nossa opinião pode ser explicada pelas características do contexto, ou seja, numa sociedade onde as pessoas tendem a manter um contato físico e emocional mais próximo, às quais se atribuem traços como o "erotismo" e a "sensualidade", o aprender pode ser tomado como um processo que se dá através desses mesmos traços (ist é emoções e sentimentos) ou nas palavras utilizadas habitualmente no Brasil, pelo "senso comum": "através do calor humano".

A questão como se aprende foi a que suscitou o maior número de categorias conceituais. No geral as respostas exprimiram a ideia de que a aprendizagem é um fenômeno humano coletivo e experiencial, ou seja, 
aprende-se através da imersão direta do indivíduo na experiência e através de um processo interacional.

Ao contrário do que aconteceu na dimensão referencial, a dimensão processual apresenta uma forte predominância de categorias "Qualitativas", consideradas dessa forma por exprimirem a ideia, confirmada inclusive pela Fenomenografia, de que a aprendizagem é um processo experiencial. Apesar disso, dentro desse quadro, a categoria "Modificando-se", aquela considerada a mais rica e produtiva, apresenta-se de forma relativamente tímida, o que nos conduz a considerar que conceber a aprendizagem como um processo vivencial necessariamente não implica aceitar que ele produzirá mudanças nos modos de ser da pessoa. $\mathrm{O}$ que impede que os estudantes que concebem a aprendizagem como um processo eminentemente experiencial não considerem também que as suas vivencias são capazes de os modificar como pessoas?

Não foi possível registrar o surgimento da categoria "Generalizando", dado que reafirma que conceber a aprendizagem como um fenômeno experiencial pode não implicar necessariamente uma postura mais compreensiva dos elementos.

A concepção de que se aprende com os outros é recorrente nesse estudo e pode ser talvez explicada pelo fato das práticas cooperativas e interacionistas de ensino e aprendizagem do contexto serem superiores às práticas individualistas. No Brasil, quer em nível social, quer em nível do ensino, parece que existe uma mentalidade marcada pelo coletivismo.

Embora atualmente vivamos numa sociedade global e por isso as pessoas possuam características comuns, as diferenças transculturais devem ser consideradas. $O$ contexto escolar está intimamente ligado à cultura do lugar no qual está inserido. Por isso é muito importante procurar perceber os fatores culturais que configuram as pessoas e a forma como essas concebem o fenômeno da aprendizagem. Esse exercício não só permitirá um melhor entendimento das particularidades do contexto e da forma como influenciam a aprendizagem como, principalmente, ajudará a aceitar e entender concepções específicas ou pelo menos com contornos específicos em meio às concepções mais universais.

A pergunta mais facilmente respondida nesse estudo ou a que provocou menos resistências parece ter sido "Onde se aprende?". A dimensão contextual (C) se apresenta como aquela dimensão em que todas as respostas expressam a ideia de que se aprende em todos os lugares e em todos os momentos. Para os estudantes aprende-se ao longo de toda a vida, seja sozinho ou com os outros. $O$ aprender é concebido como um fenômeno que abarca toda a existência e ultrapassa largamente o contexto escolar e a instrução. Esse dado é coerente com a ausência da concepção "Institucional" e com concepções de aprendizagem mais experienciais e vivenciais. 
A faculdade é vista como mais um local, sem contudo ter sido referida como um lugar específico e particularmente importante, por isso sugerimos que, como instituição favorecedora de aprendizagens acadêmicas, forneça meio necessário ao desenvolvimento da tomada de consciência dos aspectos implicados na aprendizagem acadêmica.

A análise desse dado permite-nos avaliar que no geral os estudantes brasileiros inquiridos podem não conceber a aprendizagem como uma atividade específica do ontexto acadêmico (aprendizagem acadêmica). Considerando-se as propostas de Vigotski(1930), parece importante que os estudantes atribuam importância à educação formal, aquela necessariamente promovida pela escola.

Por outro lado, tal dado pode significar uma valorização das concepções atuais de aprendizagem, que realçam a importância do aprender ao longo de toda a vida e em diferentes contextos. Assim, faz sentido perguntarmo-nos até que ponto essa visão de aprendizagem é compartilhada e otimizada pelos professores, o que nos leva a indicar investigações na área das concepções de aprendizagem em professores universitários brasileiros.

Existe uma forte ligação entre aquilo que se considera que é aprender, a forma como aprende e o lugar onde se aprende. Se esses dados no geral podem denotar, por um lado, que o aprender não é visto como uma atividade específica (acadêmica), o que nos levaria a sugerir atitudes favoráveis às aprendizagens mais concretas e menos longínquas, por outro, podem revelar uma coerência com as visões mais atualizadas e, em nossa opinião, mas apropriadas, da aprendizagem, tomando esta como uma atividade experiencial e vivencial, que pode ser utilizada para meIhorar a vida das pessoas ao longo do tempo.

Entretanto, para que esse potencial não seja desperdiçado, os contextos (professores e outros intervenientes) devem da mesma forma estimular aprendizagens vivenciais, que possam ser transferidas para o contexto alargado da vida pessoal dos estudantes, o que implica práticas de ensino mais abertas (voltadas preferencialmente para a compreensão dos fenômenos).

Considerando a semelhança dos resultados deste estudo com os resultados encontrados nas investigações de Rendeiro e Duarte (2005) e Rebelo e Duarte (em preparação), confirmamos a hipótese de que as concepções de aprendizagem se referem aos aspectos gerais do aprender, ultrapassando a natureza das tarefas acadêmicas específicas. Assim, as concepções para atividades específicas se associariam ou podem refletir as concepções de aprendizagem em geral. Da mesma forma, a correspondência com os resultados encontrados por Rosário et al. (2006) pode sugerir que algumas concepções podem ser transversais aos vários períodos acadêmicos. 
Atendendo a necessidade de realizar investigações que se centrem no "estudante em contexto" (Marton, 1988), as concepções de aprendizagem devem ser compreendidas tomando em consideração as componentes culturais do entorno dos estudantes. Assim, refletiremos sobre a relação das concepções apresentadas pelos estudantes deste estudo e as características da cultura na qual estão inseridos.

Alguns antropólogos, sociólogos e historiadores brasileiros defendem que existem no Brasil alguns traços culturais acentuados, entre os quais: a cordialidade, a preferência por relacionamentos pessoais afetivos, potenciados por uma valorização da família paternalista como nor teadora das relações sociais, e o erotismo (Ribeiro, 1995; Holanda, 1997).

A concepção segundo a qual se aprende com os outros (consistentemente aludida por esse grupo) pode refletir a noção de que os brasileiros de todos os tipos tendam a interagir mais facilmente na vida diária. Gannon (2000) refere que no Brasil existe uma voluntariedade para cultivar laços pessoais contínuos marcados pelo calor humano.

Hofstede (1991) desenvolveu uma pesquisa em sessenta países, em que procurou explicar a influência dos traços culturais nacionais e considerou o Brasil como um país coletivista, onde as redes são mais profundas, as pessoas esperam a proteção do grupo e o fornecimento de segurança em troca de lealdade.

Outro traço sugerido por Gannon (2000) é a espontaneidade da cultura brasileira. Essa hipótese da espontaneidade pode traduzir-se no oferecimento de menos importância ao tempo (físico) e à programação, frequentemente vista simplesmente como uma formalidade. Esse traço pode estar associado às concepções de aprendizagem que destacam que se aprende observando, experimentando, vivenciando, de forma instintiva ou de forma natural, não só num contexto (ambiente, espaço, tempo) específico, mas principalmente no contexto alargado da vida pessoal e coletiva do estudante.

O ponto de vista segundo o qual se aprende através das emoções, sentimentos e afetos também parece traduzir um traço cultural do Brasil. Como afirma Gannon (2000), o calor humano é aparente na cultura brasileira. Talvez aprender com os sentimentos possua alguma relação com o erotismo e a sensualidade atribuída ao povo brasileiro.

A concepção que realça a ideia de que se aprende ensaiando e errando pode manifestar aquilo a que Gannon (2000) chama de "circularidade de pequena etapa". A noção de fases curtas e orbiculares pode ser percebida, por exemplo, a partir do sistema monetário. Desde 1940, o Brasil usou cinco moedas correntes diferentes: os réis, o cruzeiro, o cruzado, o cruzeiro novo e, atualmente, o real.

A tarefa de procurar perceber as concepções de aprendizagem considerando os traços culturais brasileiros de modo algum esgota-se, dada a complexidade de tal empreendimento, por isso esperamos que as hi- 
póteses sugeridas aqui sirvam apenas como possibilidades para novas leituras e mais reflexões e investigações nessa área.

\section{Conceptions of learning in brazilian university students}

Abstract: This article reports partial results of a study that sought to characterize the conceptions of learning of Brazilian university students, in the framework of the phenomenographic perspective. Among other dimensions, a group of students was interviewed about the meaning, the process and the context of learning. The responses were subjected to a content analysis. This analysis has demonstrated a replication of most conceptions of learning described by phenomenographic research (i.e. the distinction between learning as memorizing and as understanding) as well as the emergence of apparently new conceptions (i.e.learning as development of notions about the topics while learning by Heart and applying acquired knowledge; learning through the mistakes; without exerting any effort or intention; instinctively or innately; collaborating; experiencing; feeling, playing and observing). Some of these concepts are interpreted in light of the participants' cultural referents.

Keywords: Learning. College students. Phenomenography.

\section{Conceptions d'apprentissage chez les étudiants universitaires brésiliens}

Résumé: Cet article présente les résultats d'une étude visant à caractériser les conceptions d'apprentissage des étudiants universitaires brésiliens dans l'élaboration de la perspective phénoménographique. Parmi les autres dimensions, un groupe d'étudiants ont été interrogé sur le sens, le processus et le contexte de l'apprentissage. Les réponses ont été soumis à une analyse de contenu. Les résultats démontrent une possibilité de reproduire la plupart des conceptions de l'apprentissage décrites par la recherche phénoménographique (à savoir, la distinction entre l'apprentissage comme la mémorisation et la compréhension) ainsi que l'émergence de nouvelles idées en apparence (à savoir, apprendre est dévélopper des idées sur les matériaux et en même temps décorer et appliquer les connaissances acquises, on apprend avec ses erreurs, sans exercer aucune intention, ni efforts, de sorte instinctive ou innée, en collaboration, avec des essais, avec des sentiment, et à 
travers des jeux). Certaines de ces conceptions sont interprétées en termes de références culturelles des participants.

Mots-clés: L'apprentissage. Étudiants universitaires. Phénoménographie.

Concepciones de aprendizage en estudiantes universitarios brasileños.

Resumen: Este artículo reporta parte de los resultados de un estudio que buscó caracterizar las concepciones de aprendizaje de estudiantes universitarios Brasileños en el marco de la perspectiva fenomenográfica. Entre otros aspectos, un grupo de estudiantes fue entrevistado sobre el significado, el proceso y el contexto de aprendizaje. Las respuestas fueron sometidas a una análisis de contenido que ha demostrado una réplica de la mayoría de las concepciones de aprendizaje descritas por la investigación fenomenográfica (es decir, la distinción entre el aprendizaje mientras que memorización y comprensión), así como la emergencia de concepciones aparentemente nuevas (es decir, aprender es desarrollar ideas sobre los contenidos y simultáneamente memorizar y aplicar los conocimientos adquiridos, se aprende a través de errores, sin ejercer ningún esfuerzo o intención, de modo instintivo o innato, mediante la colaboración, a través de la vida, de los sentimientos, de los juegos y de la observación). Algunas de estas concepciones son interpretadas de acuerdo con las referencias culturales de los participantes.

Palabras clave: Aprendizaje. Estudiantes universitários. Fenomenografía.

\section{Referências}

Almeida, L., \& Soares, A. (2004). Os estudantes universitários: sucesso escolar e desenvolvimento psicossocial. In E. Mercuri \& S. Polydoro (Eds.), Estudante universitário: características e experiências de formação (pp. 15-40).Taubaté, SP: Cabral Editora e Livraria Universitária.

Ausubel, D. P., Novak, J. D., \& Hanesian, H. (1978). Educational Psychology: A Cognitive View. New York: Holt, Rinehart \& Winston.

Biggs, J. (1989). Approaches to the enhancement of tertiary teaching. Higher Education Research and Development, 8(1), 7-25. 
Biggs, J. (1990). Teaching for desired learning outcomes. In N. Entwistle (Ed.), Handbook of educational ideas and pratices (pp. 681-693). London and New York: Routledge.

Biggs, J., \& Moore, P. (1993). The process of learning. New York: Prentice Hall.

Cliff, A. (1998). Teacher-learners' conceptions of learning: Evidence of a "communalist" conception amongst postgraduate learners? Higher Education, 35(2), 205-220.

Craik, F., \& Lockhart, R. (1972). Levels of processing: A framework for memory research. Journal of Verbal Learning \& Verbal Behavior, 11, 671-684.

Duarte, A. (2000). Avaliação e modificação de concepções, motivações e estratégias de aprendizagem em estudantes do ensino superior. Tese de Doutorado, Faculdade de Psicologia da Educação, Universidade de Lisboa, Lisboa.

Duarte, A. (2004). Concepções de aprendizagem em estudantes universitários (as) portugueses (as). Revista Portuguesa de Psicologia, 18(1), 147-163.

Eklund-Myrskog, G. (1998). Student's conceptions of learning in different educational contexts. Higher Education, 35, 299-316.

Entwistle,N.(1984). Contrasting perspectives on learning. In F.Marton., D. Hounsell \& N. Entwistle (Eds.), The experience of learning (pp. 1-18). Edinburgh: The Scottish Academic Press.

Flores, J. (1994). Análises de datos cualitativos: aplicacione a la investigación educativa. Barcelona: PPV.

Freire, P. (2003). Educação e mudança. São Paulo: Editora Paz e Terra.

Gannon, M. (2000). Cultural metaphors: Readings, research translations, and commentary. California: Sage.

García, C. (1992). Dar sentido a los datos: la combinación de perspectivas cualitativo y cuantitativo en el análisis de entrevistas. In C. Garcia (Ed.), La investigación sobre la formación del profesorado, métodos de investigación y análisis de datos (pp. 13-48). Argentina: Cincel.

Grácio, M. (2002). Concepçôes do aprender em estudantes de diferentes graus de ensino: do final da escolaridade obrigatória ao ensino superior: uma perspectiva fenomenográfica. Tese de Doutorado, Universidade de Évora, Évora.

Hofstede, G. (1991). Culture and organizations: Software af the mind. New York: McGrawhill. 
Holanda, S. (1997). Raízes do Brasil. São Paulo: Companhia das Letras.

Laurillard, D. (1979). The process of student learning. Higher Education, 8, 395409.

Litto, F. (n.d.). Aprendizagem profunda e aprendizagem de superfície.Texto recuperado em 10 de julho, 2007,de http://www2.uol.com.br/aprendiz/n_colunas /f_litto/id171000.htm

Marton, F. (1981). Phenomenography - describing conceptions of the world around us. Instituctional Science, 10, 177-200.

Marton, F. (1988). Describing and improving learning. In R.Schmeck (Ed.), Learning strategies and learning styles (pp. 36-55). New York: Plenum.

Marton, F., \& Booth, S.(1997). Learning and awareness. Mahwah:Lawrence Erlbaum.

Marton, F., Dall'Alba, G., \& Beaty, E. (1993). Conceptions of learning. International Journal of Educational Reserch, 19(3), 277-300.

Marton, F., \& Fai, P. (1999). Two faces of variation. Paper presented at $8^{\text {th }}$ European conference for learning on instruction: Göteborg: Göteborg University.

Marton, F., \& Säljö, R. (1976). On qualitative differences In learning - I. Outcome and process. Brittish Journal of Educational Psychology, 46, 4-11.

Marton, F., \& Säljö, R. (1997). Approaches to learning. In F. Marton, D. Hounsell \& N. Entwistle (Eds.), The experience of learning (pp. 39-58). Edinburgh: Scottish Academic Press Limited.

Mercuri, E., \& Polydoro, S. (2004). O compromisso com o curso no processo de permanência / evasão no ensino superior:algumas contribuições. In E.Mercuri \& S. Polydoro (Eds.), Estudante universitário: características e experiências de formação (pp. 219-236). Taubaté: Cabral Editora e Livraria Universitária.

Miles, M., \& Huberman, A. (1994). Qualitative data analysis: And expanded sourcebook. California: Sage.

Rebelo, M., \& Duarte, A. (em preparação). Concepções de aprendizagem com o computador em estudantes universitários.

Rendeiro, A., \& Duarte, A. (2007). Concepções de aprendizagem face à avaliação em estudantes do ensino secundário. In A. Simão., A. Silva \& I. Sá (Eds.), Autoregulação da aprendizagem: das concepções às práticas (pp. 63-92). Lisboa: ED - Ui \& DCE. 
Rosário, P., Mendes, M., Grácio, M., Chaleta, E., González-Pienda, J., \& HernándezPina, F. (2006). Discursos de pais e alunos sobre o aprender: um estudo no $5^{\circ}$ ano de escolaridade. Psicologia em Estudo, 11(3), 463-471. Recuperado em 10 de julho, 2006, da SciELO (Scientific Electronic Library OnLine): http:// www.scielo.br/scielo.php?pid=S1413-73722006000300002\&script=sci_arttext

Säljö, R. (1984). Learning from reading. In F. Marton, D. Hounsell \& N. Entwistle (Eds.), The experience of learning (pp. 71-89). Edinburgh: Scottish Academic Press.

Ribeiro, D. (1995). O povo brasileiro. São Paulo: Companhia das Letras.

Zimmerman, B. (1998). Academic studying and the development of personal skill: A self-regulatory perspective. Educational Psychologist, 33, 73-86. 
Luiz Gustavo Lima Freire, Doutorando em Psicologia da Educação, Universidade de Lisboa, Faculdade de Psicologia, Lisboa, Portugal. Bolsista da Fundação de Apoio à Ciência e à Tecnologia (FCT), a quem agradece o incentivo. Endereço para correspondência: Faculdade de Psicologia da Universidade de Lisboa, Alameda da Universidade, 1649-013, Lisboa, Portugal. Endereço eletrônico: luizgustavolfreire@ig.com.br

António Manuel Duarte, Professor Auxiliar da Universidade de Lisboa, Faculdade de Psicologia.Endereço para correspondência:Faculdade de Psicologia da Universidade de Lisboa, Alameda da Universidade, 1649-013, Lisboa, Portugal. Endereço eletrônico: amduarte@fp.ul.pt

Recebido: 26/11/2009

Aceito: 02/09/2010 